\title{
Highly efficient and recyclable silver-graphene oxide nano-composite catalyst in the acylation of amines under solvent-free condition
}

\begin{abstract}
A silver and graphene oxide nanocomposite (Ag-GO) has been prepared by a facile chemical approach and analyzed by usual manner, such as powder x-ray diffraction (pXRD), scanning electron microscopy (SEM) transmission electron microscopy (TEM), UV-visible spectra (UV-vis) and thermogravimetric analysis (TGA). Ag-GO acts as a proficient heterogeneous nanocomposite catalyst demonstrating excellent catalytic activity for the acylation of amines with acetic acid without any solvent. Moreover, the catalyst is smoothly recoverable, and may be reused five times with no loss of catalytic activity toward the acylation of amines with acetic acid. It is expected that the silver-graphene oxide nanocomposite will find application in various catalytic fields.
\end{abstract}

Keywords: graphene oxide; silver nanoparticle, nanocatalyst, acylation, amines
Volume 2 Issue 4 - 2018

\author{
Prasenjit Mandal, Aritra N Chattopadhyay, \\ Asoke P Chattopadhyay \\ Department of Chemistry, University of Kalyani, India
}

Correspondence: Asoke P Chattopadhyay, Department of Chemistry, University of Kalyani, Kalyani 741235 , India, Tel +91332582 8750, 305/308, 25829699 (Res), Fax 25828282 Email asoke@klyuniv.ac.in, asoke.chattopadhyay@gmail.com

Received: August 02, 2018 | Published: August 13, 2018

\section{Introduction}

Development of non-toxic, eco-friendly, low cost and recyclable catalysts, which give high productivity under mild reaction conditions, is a matter of interest to synthetic chemists nowadays. In this context, there is a huge potential for relevant nanomaterials to be used as catalysts to improve the selectivity and yield of various catalytic processes. This is because of their unique surface features, which are essentially different from those of corresponding bulk materials. ${ }^{1,2}$ Nanomaterials have secured wide application in several areas such as consumer electronics, optics, catalysis, surface coating, pharmaceuticals, sensors etc. ${ }^{3}$ In nanocatalyst, bigger surface to volume ratio implies large number of active sites which participate in reactions. Further, there are self-assembled nanoparticles made by a variety of diverse ways which are gaining importance in recent years ${ }^{4}$ Such type of nanoparticle-based catalysts are generally attached to solid materials such as carbon nanotubes, graphene, activated carbon, zeolites, silica or polymeric materials for facile separation..$^{5-8}$ Among these, graphene and graphene oxide (GO) are considered as better supporting materials for their larger surface area and high conductivity. However, identical and controlled loading of several nanocatalyst and how to stabilize the catalyst on the support without loss of catalytic efficiency are interesting and challenging issues. ${ }^{9,10}$

Graphene has a structure that is like a two-dimensional nanosheet. It provides an amazing geometrical support for nanocomposite molecular catalysts. One reason is its large surface area, which is easily accessible to reactant molecules. Also, the diffusion barrier may be small, which is different from other porous catalytic materials, leading to easy electron transfer above the hybrid 2D carbon network. ${ }^{9,10}$ Such sp2 hybrid carbon-based nanostructures have been most widely studied as supports for both electro catalysis and heterogeneous catalysis, due to their bigger surface area, high mechanical strength, excellent electrical conductivity, and stability under drastic conditions. ${ }^{9}$ Graphene-based nanocomposites have been prepared to enhance the efficiency of electrocatalysis, ${ }^{11-14}$ photo catalytic reaction, ${ }^{15}$ carboncarbon bond formation, ${ }^{16,17}$ redox catalysis, ${ }^{18}$ and in Li-ion batteries. ${ }^{19}$ Heterogeneous nature of the catalyst is highly desirable, along with its reusability and thermal stability. ${ }^{20}$
Silver metal is well known for its high electrical conductivity ${ }^{21}$ and bactericidal action. ${ }^{22-25}$ Silver nanoparticles have also found application in catalysis, clothing, medicinal coverings e.g. bandages, photovoltaics, as sensor materials etc. ${ }^{26,27}$ Hence its nanocomposite with GO may lead to enhancement of certain feature of catalysis and may create a novel composite material with desirable characteristics. In organic chemistry, acylation of amines is one of the most widely studied reaction. ${ }^{28,29}$ Moreover, $\mathrm{N}$-acetylation is a reaction which is important in the field of biology, pharmaceutical, and agricultural industries ${ }^{30-33}$ From both economic and environmental standpoints, conversion of amines to the corresponding acetamides using acetic acid is an attractive proposition. There are a number of methods for this particular process, including various types of catalysts, ${ }^{34-36}$ but they are fraught with disadvantages e.g. costly nature of the catalyst, susceptibility of the catalyst to many products and intermediates leading to short working life of the catalyst, relatively longer reaction times and low yield etc. Hence a reasonably cheaper and efficient catalyst, which can be used many times, would be in some demand. Here, the silver-graphene oxide (Ag-GO) nanocomposite was investigated as heterogeneous catalyst for the acylation of amines with the help of acetic acid. The separation of the catalyst can be easily done by simple filtration, and the catalyst can be reused at least five times without significant loss of catalytic activity.

\section{Experimental}

\section{Materials}

Graphite powder was purchased from Asbury Graphite Mill, Inc. (Asbury, NJ, USA) and used as received. GO (graphene-oxide) was prepared from graphite using a modified Hummer's method. ${ }^{13}$ Briefly, graphite was oxidized to graphite oxide with sulfuric acid $\left(\mathrm{H}_{2} \mathrm{SO}_{4}\right)$ and potassium permanganate $\left(\mathrm{KMnO}_{4}\right)$, and hydrogen peroxide $\left(\mathrm{H}_{2} \mathrm{O}_{2}\right)$ was added to stop the oxidation. Graphite oxide was washed with simple decantation of the supernatant with repeated centrifugation and washing until $\mathrm{pH} 7.0$ was achieved, and followed by exfoliation in an ultrasonication bath. The analytical-grade $\mathrm{AgNO}_{3}$ (silver nitrate), sodium nitrate, sodium borohydride ( $>99 \%$, S.D. Fine, India), $\mathrm{H}_{3} \mathrm{PO}_{4}$ , $\mathrm{KMnO}_{4}(>99 \%$, Nice, India), hydrogen peroxide (30\%), sulphuric acid (98\%), Acetic acid (glacial 99-100\%) and SDS used in this study 
were purchased from Merck (Darmstadt, Germany), and used without further purification. The other chemicals were all analytical grade, used as received, and the water used was deionized.

\section{Characterization techniques}

Synthesis of Ag-GO nanocomposite was monitored by UV-vis spectroscopy. UV-vis spectra were recorded between 200 and $900 \mathrm{~nm}$ using a Specord 200 (Analytik Zena, Germany) spectrometer. The Fourier transform infrared (FT-IR, Tensor 27, Bruker, Germany) spectra were recorded using a ZnSe prism. The angle of incidence of the IR radiation was maintained at 450 over the wave number range $4000-1000 \mathrm{~cm}^{-1}$, and 200scans were obtained and averaged with a resolution of $4 \mathrm{~cm}^{-1}$. Powder X-ray diffraction (pXRD) patterns were obtained using a Rigaku Miniflex-4000 Diffractometer $(\mathrm{Cu} \mathrm{Ka}$ line at $1.5406 \AA, 40 \mathrm{kV} / 20 \mathrm{~mA}$ ) and were recorded at angles between 100 and 800 , with a scan rate of $20 \mathrm{~min}^{-1}$ and scan step of 0.020 . Powder XRD pattern was taken again after 5cycles of acylation of aniline with acetic acid, with Ag-GO nanocomposite as catalyst, using Bruker D8 Avance diffarctometer, rest of the parameters remaining the same. Atomic Absorption Spectrometry (AAS) was carried out on the nanocomposite using Shimadzu AA-6300 Atomic Absorption Spectrophotometer. Scanning electron microscopy (SEM) images of silver nanoparticles (Ag NPs) and Ag-GO were observed in a Hitachi S-4800 FE-SEM (field-emission scanning electron microscope). Sample for TEM (Transmission electron microscopy) was prepared dropping $10 \mu \mathrm{L}$ of aqueous solution of $\mathrm{Ag}-\mathrm{GO}$ onto a carbon-coated copper grid and allowing the solvent to evaporate in a vacuum chamber. TEM images were obtained using a Jeol JEM$2100 \mathrm{~F}$ transmission electron microscope operated at an accelerating voltage of $200 \mathrm{kV}$. Atomic Force Microscopy (AFM) was carried out with a Veeco Innova instrument in tapping mode. Raman spectra were recorded on a LabRAM HR (Jobin Yvon) spectrometer with an air cooled Ar ion laser and Peltier-cooled CCD detector.

\section{Preparation of graphene oxide (GO)}

Graphene oxide (GO) sheets were synthesized by modified Hummers' method. ${ }^{14}$ Briefly, graphite flakes $(5 \mathrm{~g})$ and $\mathrm{NaNO}_{3}$ (sodium nitrate, $2.5 \mathrm{~g}$ ) were mixed with $\mathrm{H}_{2} \mathrm{SO}_{4}$ (sulfuric acid, $80 \mathrm{~mL}$ ) and $\mathrm{H}_{3} \mathrm{PO}_{4}$ $(8 \mathrm{~mL})$ in an ice bath under stirring condition for $3.5 \mathrm{~h}$. After that, $10 \mathrm{~g}$ $\mathrm{KMnO}_{4}$ (potassium manganate) was added. The reaction mixture was kept at $25^{\circ} \mathrm{C}$ for $1.5 \mathrm{~h}$, diluted with $160 \mathrm{~mL}$ water, and further diluted by the addition of $560 \mathrm{~mL}$ warm water after keeping the temperature at $80^{\circ} \mathrm{C}$ for another $3.5 \mathrm{~h} . \mathrm{H}_{2} \mathrm{O}_{2}$ (Hydrogen peroxide, $15 \mathrm{~mL}$ ) was then added to reduce the residual $\mathrm{KMnO}_{4}$. Stirring continued for $5 \mathrm{~h}$ until the mixture turned to yellow. Finally, the mixture was centrifuged to obtain the powder of graphene oxide (GO). To clean any leftover salt, the GO powder was washed with $\mathrm{HCl}(10 \%)$ and then dispersed again in deionized water and centrifuged again. The GO powder was finally dried under vacuum. The graphite oxide was exfoliated into GO multilayer sheets by soni cation for $1.5 \mathrm{~h}$ after dispersion in water.

\section{Synthesis of silver-graphene oxide nanocomposite (Ag-GO)}

The typical procedure for the synthesis of Ag-GO nanocomposite (silver-graphene oxide) was followed. $73.6 \mathrm{mg}$ of sodium dodecyl sulfate (SDS) was completely dissolved in $25 \mathrm{~mL}$ of deionized water under soni cation for about $20 \mathrm{~min}$ by water bath sonicater to from a clear solution at room temperature. Then $12.23 \mathrm{mg}$ of $\mathrm{AgNO}_{3}$ solution $(0.03 \mathrm{M})$ was added to it. After stirring for $2.5 \mathrm{~h}$, formation of SDS- capped silver nitrate colloid was observed. $78 \mathrm{mg}$ graphene oxide powder was dispersed in $25 \mathrm{~mL}$ of deionized water by sonication for 45 minute to form a stable graphene oxide colloid. Finally, the $\mathrm{AgNO}_{3}$ colloid was mixed with GO colloid and $1 \mathrm{~mL}$ of acetic acid was added to the whole mixture. The mixed solution was heated to boil, then cooled to r.t. (room temperature) and was continually stirred at the same temperature for $2 \mathrm{~h} .2 \mathrm{~mL}$ of $\mathrm{NaBH}_{4}(0.0118 \mathrm{M})$ solution was added drop wise to it. The solution became greenish-yellow in color, indicating formation of $\mathrm{Ag}-\mathrm{GO}$ nanocomposite. The product was repeatedly washed with deionized water and centrifuged $(10,000 \mathrm{rpm}$ for $15 \mathrm{~min}$ ) to remove excess chemicals and then dried under vacuum. It is to be noted that without $\mathrm{NaBH}_{4}$, no $\mathrm{Ag} \mathrm{NPs}$ were formed on the GO matrix, as observed by UV-Vis Spectroscopy and powder XRD methods (Supplementary Figures).

\section{General procedure for acylation of amines using silver- graphene oxide (Ag-GO) nanocatalyst}

In aniline $(0.9 \mathrm{~mL}, 10 \mathrm{mmol})$, acetic acid $(0.6 \mathrm{~mL}, 10 \mathrm{mmol})$ and $\mathrm{Ag}$ GO nanocomposite $(25 \mathrm{mg})$ in a procedure of typical acylation reaction were heated together to a temperature of $900 \mathrm{C}$ which is kept in a $50 \mathrm{~mL}$ round bottomed flask. The hot mixture of the reaction was diluted after $4 \mathrm{~h}$ with ethyl acetate and by filtration; the catalyst was removed from the mixture of reaction. The catalyst was regenerated, and used for five consecutive cycles to study the efficiency of recycling. With the help of saturated sodium bicarbonate solution, the filtrates were washed and then dried over $\mathrm{Na}_{2} \mathrm{SO}_{4}$ (anhydrous sodium sulfate). The progress of reaction was studied by collecting the reaction mixture at different time intervals, and analyzing the aliquots by GC and GC-MS (Figure 1).

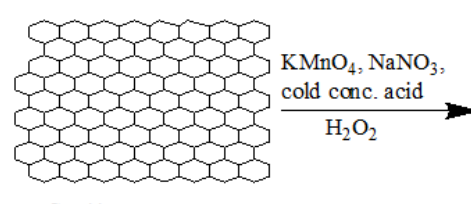

Graphite

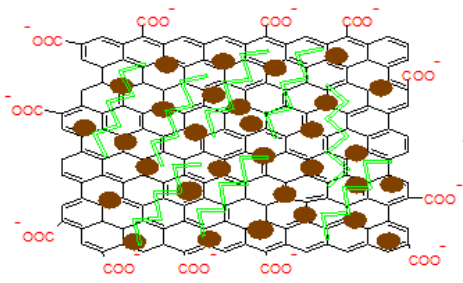

Graphene oxide-Ag NP nanocomposite
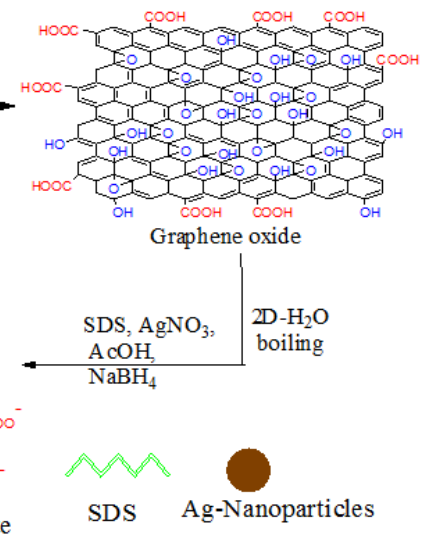

Figure I Schematic process for the synthesis of Ag-GO nanocomposite.

\section{Results and discussion}

\section{Characterization of catalyst: FTIR study}

The FTIR spectra of GO (bottom) and Ag-doped GO (top) nanocomposite are shown in Figure 2. The strong band at $3401.63 \mathrm{~cm}^{-1}$ in the spectrum of GO is due to $\mathrm{O}-\mathrm{H}$ stretching. The presence of a band at approximately $1636.24 \mathrm{~cm}^{-1}$ corresponds to the $\mathrm{C}=\mathrm{C}$ bond stretch of the aromatic rings of the GO carbon skeleton structure. ${ }^{37-39}$ The band at $1749.27 \mathrm{~cm}^{-1}$ is due to the $\mathrm{C}=\mathrm{O}$ stretch of carboxylic or carboxylate moiety. The stronger band at $1052.1 \mathrm{~cm}^{-1}$ is due to $\mathrm{C}-\mathrm{O}$ group of GO. For the $\mathrm{Ag}-\mathrm{GO}$ nanocomposite, the $\mathrm{O}-\mathrm{H}$ stretch, aromatic $\mathrm{C}=\mathrm{C}$ stretch and $\mathrm{C}=\mathrm{O}$ all shift to lower energy values at $3143.19 \mathrm{~cm}^{-1}, 1549.50 \mathrm{~cm}^{-1}$, and $1718.89 \mathrm{~cm}^{-1}$ respectively. So the FTIR spectra of GO and Ag- 
doped GO indicate significant decrease in the intensity of the bands of oxygenated functional groups in the Ag-GO nanocomposite vis-a-vis that in GO. Possible existence of AgNP on the surface of GO, and slight reduction of $\mathrm{GO}$ by $\mathrm{NaBH}_{4}$ are also indicated.

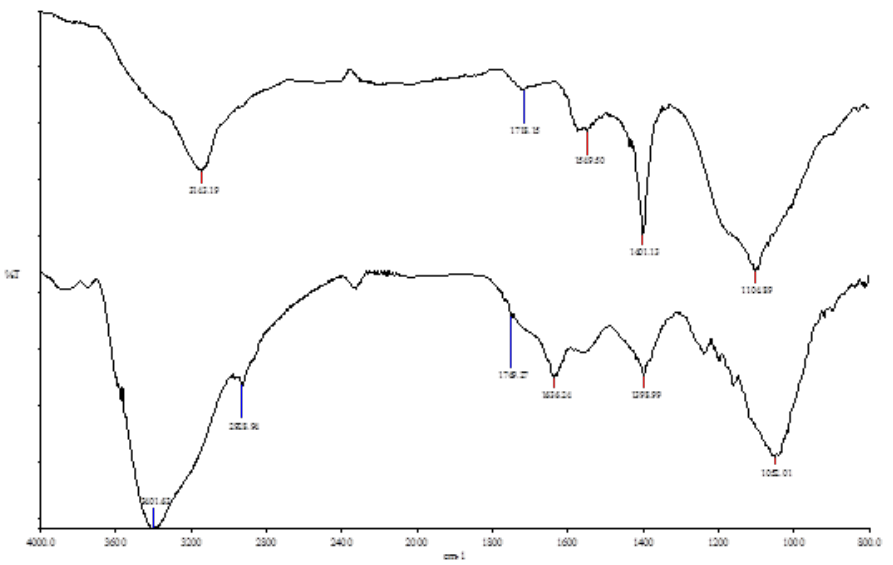

Figure 2 FTIR spectrum of GO (bottom) and Ag-doped GO nanocomposite (top).

\section{SEM Study}

The SEM image of Ag-GO nanocomposite showed in Figure 3. The morphology was characterized by flaky GO sheets or platelets stacked together. Presence of Ag nanoparticles is not apparent in the figure, but is seen clearly in the EDX diagram. The EDX analysis of the Ag-GO nano-composite is shown below Figure 4. While peaks for $\mathrm{C}$ and $\mathrm{O}$ atoms appear close to the origin, the $\mathrm{Ag}$ peak is seen at around $3 \mathrm{keV}$, again confirming presence of silver in the Ag-GO nanocomposite. The actual amount of $\mathrm{Ag}$ in the nanocomposite was ascertained by AAS as $4.07 \%(\mathrm{w} / \mathrm{w})$.

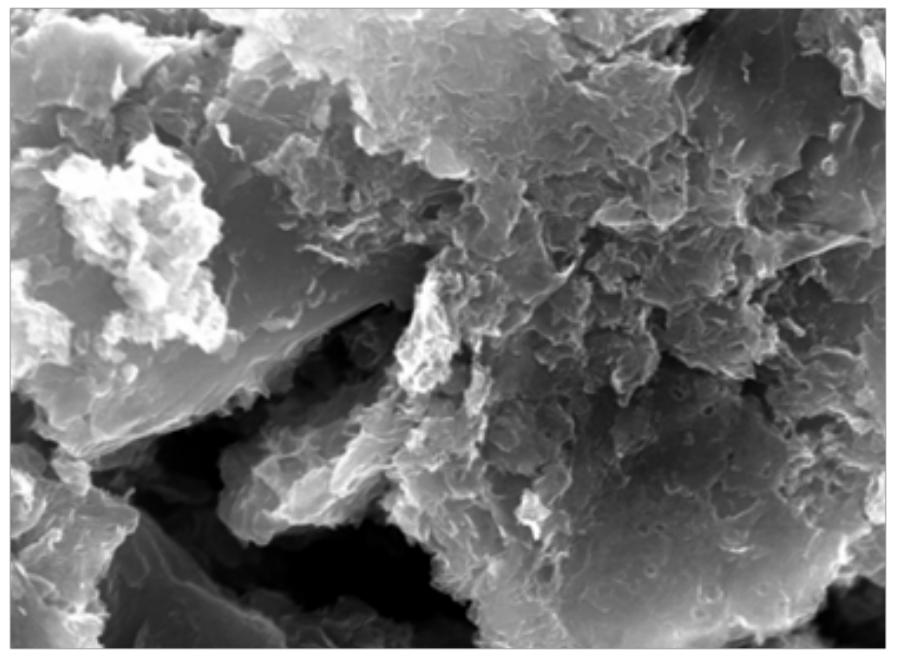

Figure 3 SEM image of Ag-GO nanocomposite.

\section{UV-visible spectroscopy}

UV-Vis spectrum of the Ag-GO sample is shown in Figure 5 (left) below. It shows a prominent plasmon peak at $408.5 \mathrm{~nm}$, which is characteristic of Ag nanoparticles. This shows that silver nanoparticles are incorporated in the graphene oxide matrix. Note that this peak is entirely absent in the UV-Vis spectrum of GO alone (Figure 5, right).

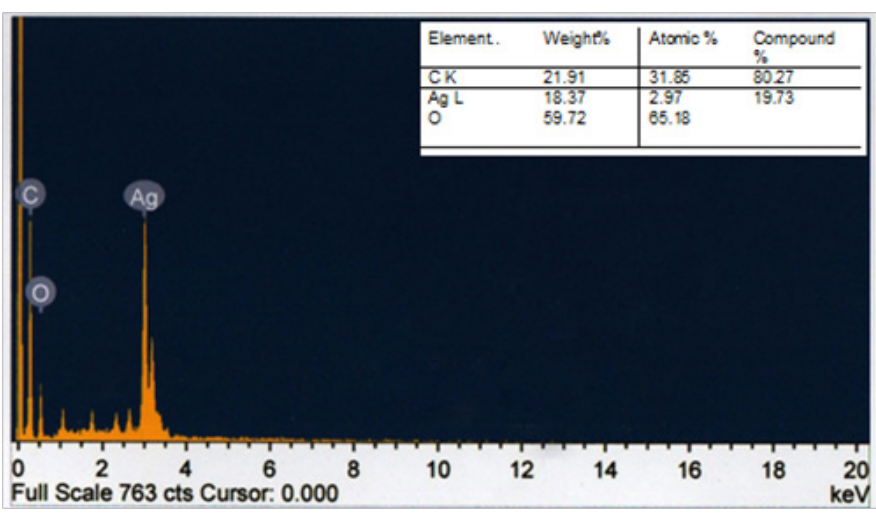

Figure 4 EDX analysis of the Ag-GO nanocomposite.
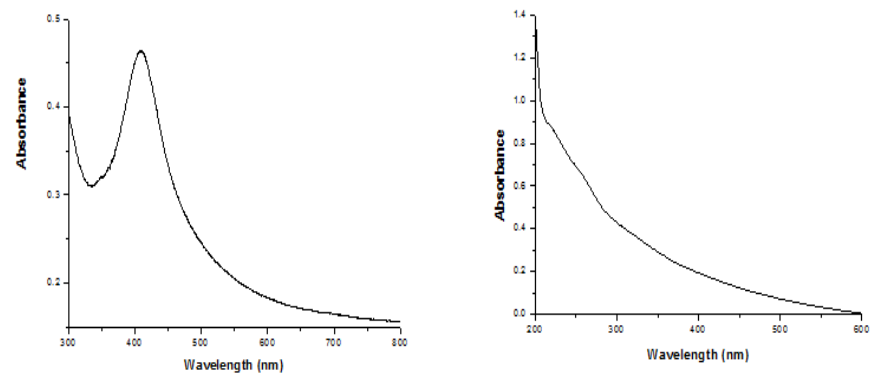

Figure 5 UV-Vis spectra of Ag-GO nanocomposite (left) and GO alone (right).

\section{XRD spectra}

Next, the powder XRD spectrum of Ag-GO is presented in Figure 6. The spectrum shows a complex, heterogeneous composite of graphene, graphene oxide and silver nanoparticles. Peaks for silver are shown in blue, those for graphene are in black, and the (002) peak of graphene oxide is shown in red. The (100) peak of graphene almost overlaps with its (101) peak and is hence represented by an asterisk. The double asterisk represents a broad peak most probably due to presence of graphite and hence is represented by an asterisk. When this is compared to the pXRD spectrum of the nanocomposite after 5cycles of use as catalyst in acylation of aniline with acetic acid, the resulting spectrum (Figure 6, right) shows almost the same set of peaks. The difference between the two may be due to two different instruments and amounts of sample being used. Also, the broad peak near $22^{\circ}$, indicating disordered structure seen in commercial graphite, has increased noticeably.

\section{Raman spectra}

The Raman spectrum of Ag-GO nanocomposite is shown in Figure 7 (left). The D and G peaks of graphene, at 1358.20 and $1587.40 \mathrm{~cm}^{-1}$, are clearly visible. The ID/IG ratio is 0.975 , showing disorder, which is also apparent from the SEM picture (Figure 3). On the right is Raman spectrum of GO alone, with D and G peaks at 1298.8 and $1593.4 \mathrm{~cm}^{-1}$ respectively.

\section{TEM study}

TEM images of Ag NP (Figure 8a) and Ag-GO nanocomposite are shown in the Figure 8b. Highly crystalline spherical Ag nanoparticles with appearance of lattice fringes can be clearly seen in the Figure 
8c. The fringe spacing of $\sim 0.239 \mathrm{~nm}$ corresponds to the (111) plane of the Ag nanoparticles. Figure 8b shows Ag-GO nanocomposite, indicating homogeneously distributed $\mathrm{Ag}$ nanoparticles on graphene oxide nanosheets. Select area electron diffraction (SAED) pattern of the nanocomposite (Figure 8d) shows polycrystalline nature of the sample. More images are given in Supplementary Information.
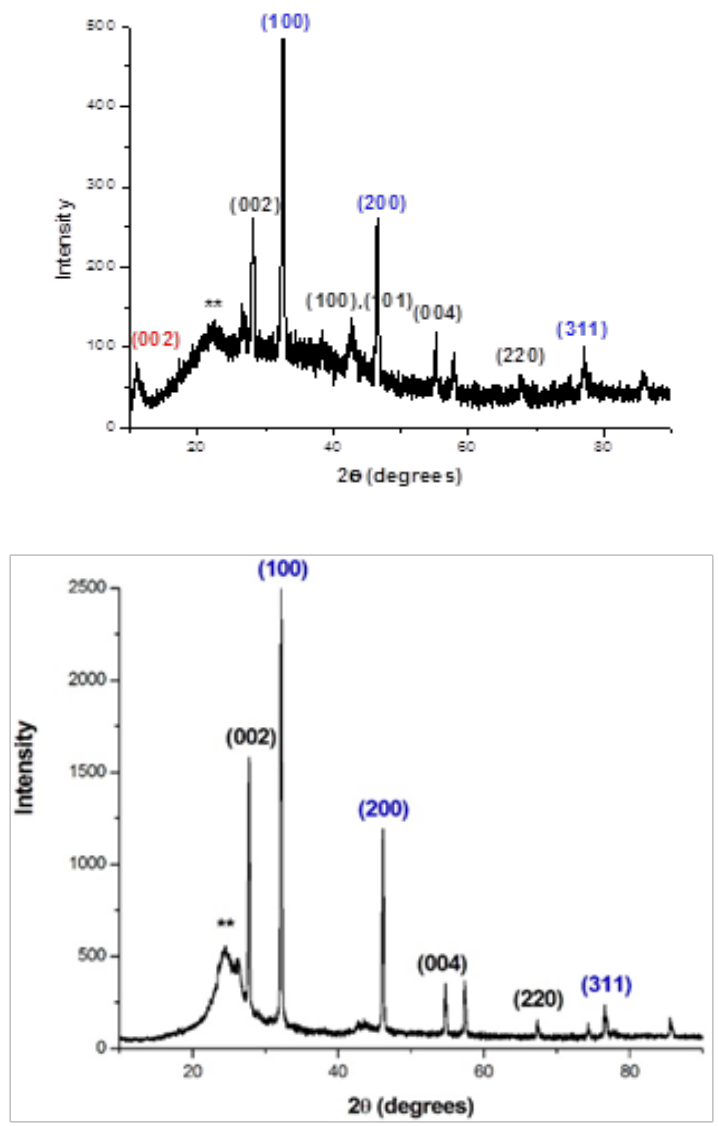

Figure 6 Powder XRD spectrum of Ag-GO nanocomposite, (left) before, and (right) after 5 cycles of use as catalyst in acylation of aniline with acetic acid.
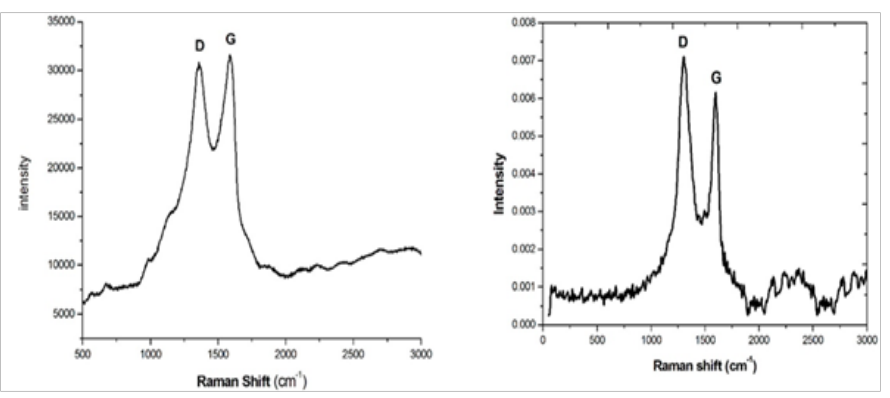

Figure 7 Raman spectrum of Ag-GO nanocomposite (left), and GO only (right).

\section{TGA Analysis}

Thermogravimetric analysis (TGA) of the Ag-GO is presented below (Figure 9), along with that of pure GO. Whereas the TGA curve for graphene oxide shows progressive and extensive loss of weight, that for Ag-GO nanocomposite is only about $12.1 \%$ till $800^{\circ} \mathrm{C}$. This indicates substantial binding of $\mathrm{Ag}$ into the GO matrix, also evident from FT-IR data, which stabilizes the entire matrix. Thickness of the nanocomposite was found to be between 0.6 to $0.8 \mathrm{~nm}$, as observed by AFM study. The data are shown as Figures $3 \& 4$ in Supplementary Information.

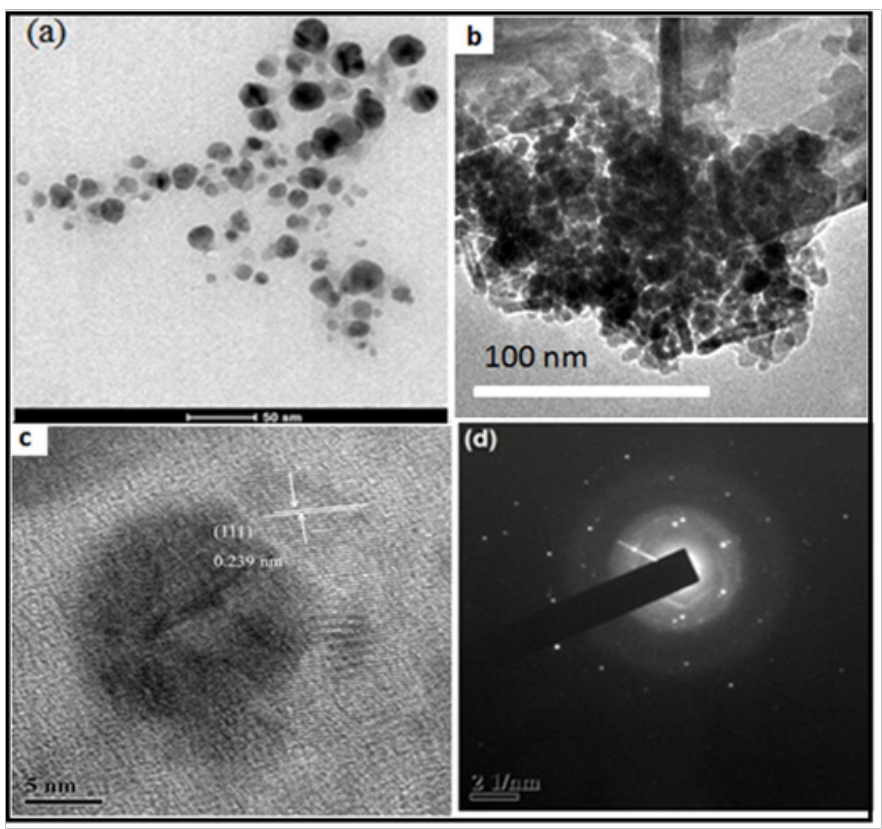

Figure 8(A) TEM images of $\mathrm{Ag} N P$ and (B) Ag-GO nanocomposite (low resolution); (C) HRTEM images of Ag-GO nanocomposite; (D) SAED pattern of $\mathrm{Ag}$-GO nanocomposite.

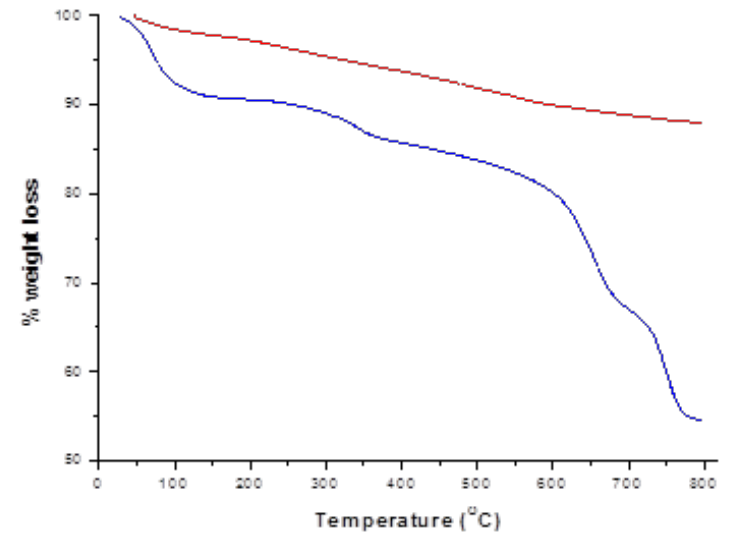

Figure 9 Thermogravimetric analysis of $\mathrm{Ag}-\mathrm{GO}$ nanocomposite (in red) vs $\mathrm{GO}$ (in blue).

\section{Catalytic activity}

\section{Acylation of amines using acetic acid catalyzed by silver-graphene (Ag-GO) nanocatalyst}

In synthetic organic chemistry, the acylation of amines is one of the most commonly used transformations to obtain amide linkage in a multistep synthetic process. Acylation of aniline, with acetic acid as the agent of acylation, was chosen as a model reaction to examine the catalytic activity silver-graphene oxide (Ag-GO) nanocomposite Figure 10. 
<smiles>CC(=O)OC(=O)O</smiles>

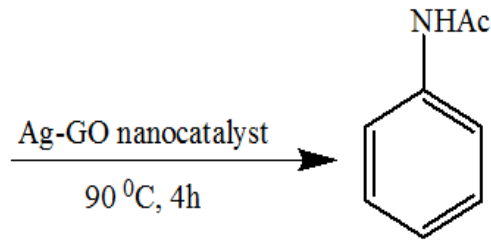

Figure 10 Acylation of aniline using acetic acid.

The reaction condition needed to be optimized as the working ability of a silver-graphene nanocomposite catalyst in acylation reaction may depend on a number of factors like solvent, reaction temperature, reaction time etc. The acylation of aniline was first carried out in presence of solvents such as acetonitrile, dichloromethane etc. and the summary of the results is given in a tabular form in Table 1. Maximum conversion of aniline to acetanilide is obtained by not using any solvent (Table 1, entry 2). As seen in Table 1, it was seen that the reaction gave excellent yield but took longer time to complete in presence of acetonitrile and dichloromethane as solvent (entries 3,4). The effect of temperature on catalytic activity was also investigated in this system. It was found that maximum yield is obtained at $100^{\circ} \mathrm{C}$ (Table 1, entry 2). Almost no conversion of aniline into acetanilide was seen in the absence of catalyst (Table 1, entry 9). Thus it was observed that the optimum yield was obtained in the acylation of aniline using acetic acid, with Ag-GO nanocomposite catalyst, at $100^{\circ} \mathrm{C}$ for $4 \mathrm{~h}$ without the presence of any solvent.

Next, the effectiveness of the Ag-GO nanocomposite as catalyst, in acylation of aniline, was compared with that of Ag NP and GO under similar experimental reaction conditions (Table 1, entries 2, 7 and 8). Product yield was highest with Ag-GO nanocomposite. While much less yield was obtained with Ag NP alone, only trace amount of product was obtained with GO. The effectiveness of AgGO nanocomposite may be due to high content of Ag exposed on the surface of Ag-GO. As better catalytic activity is exhibited by the nanocomposite than pure silver, it may be concluded that combining silver with graphene or GO enhances the catalytic activity of silver. This may be due to the following factors:

i. GO (and graphene) has highly mobile electrons, which may play an important role in enhancing catalytic activity of the nanocomposite;

ii. In comparison to silver NPs and GO by themselves, Ag-GO nanocomposite can provide a platform where Ag NPs can be dispersed. Hence Ag-GO nanocomposite prevents agglomeration of Ag NPs, provides a high surface area and more active sites for reaction;

iii. Also, GO may not work only as support, but may also promote catalytic activity of Ag NPs in the reaction

Table I Optimization of reaction conditions for the acylation of aniline with acetic acid using Ag-GO nanocomposite ${ }^{a}$

\begin{tabular}{llllll}
\hline Entry & Temperature $\left({ }^{\circ} \mathbf{C}\right)$ & Solvent & Time $(\mathbf{h})$ & Yield $(\%)^{\mathbf{b}}$ & Catalyst \\
\hline I & 140 & - & 3 & 79 & Ag-GO nanocomposite \\
2 & 100 & - & 3 & 97 & do \\
3 & 80 & $\mathrm{CH}_{3} \mathrm{CN}$ & 10 & 52 & do \\
4 & $\mathrm{RT}$ & $\mathrm{CH}_{2} \mathrm{Cl}_{2}$ & 24 & 70 & do \\
5 & 100 & - & 14 & 53 & do \\
6 & 100 & - & 24 & 30 & do \\
$7^{c}$ & 100 & - & 3 & 69 & $\mathrm{Ag}(0)$ \\
$8^{\text {d }}$ & 100 & - & 3 & trace & $\mathrm{GO}$ only \\
$9^{\mathrm{e}}$ & 100 & - & 3 & trace & No catalyst \\
\hline
\end{tabular}

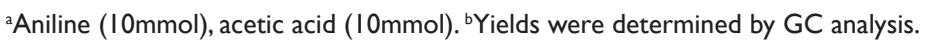

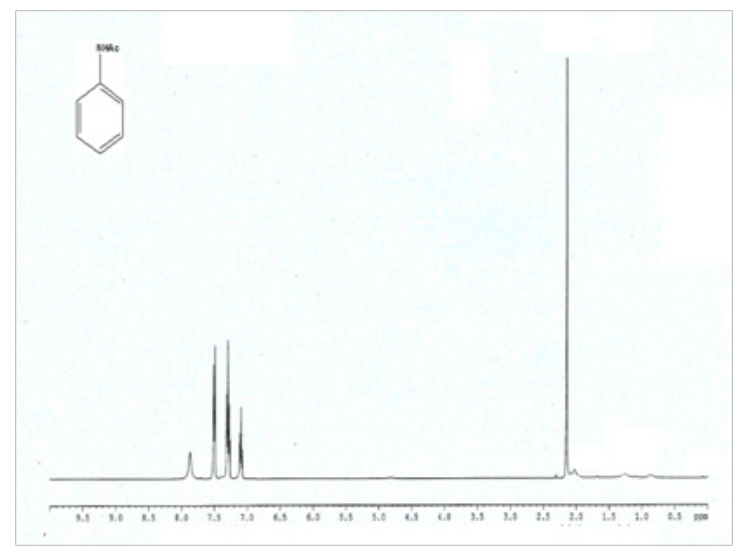

Entry I (Table 2) 'H NMR (400 MHz; $\left.\mathrm{CDCl}_{3}\right) \delta 7.70(\mathrm{br}, \mathrm{IH}), 7.5$ (d, 2H), $7.3 \mathrm{I}(\mathrm{t}, 2 \mathrm{H}, \mathrm{J}=7.3 \mathrm{~Hz}), 7 . \mathrm{II}(\mathrm{t}, \mathrm{IH})$;

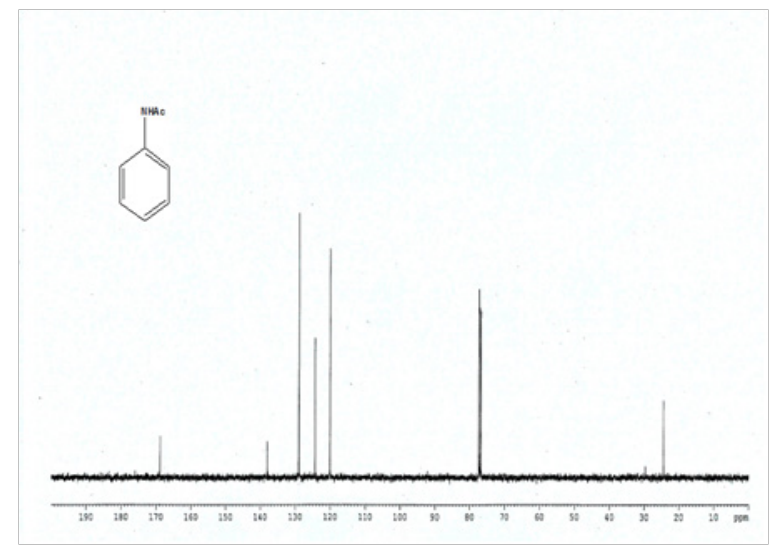

Entry I (Table 2) ${ }^{13} \mathrm{C}$ NMR $\left(100 \mathrm{MHz} ; \mathrm{CDCl}_{3}\right) \delta$ I68.6, I37.8, 128.9, I24.2, 119.9, 24.4. 


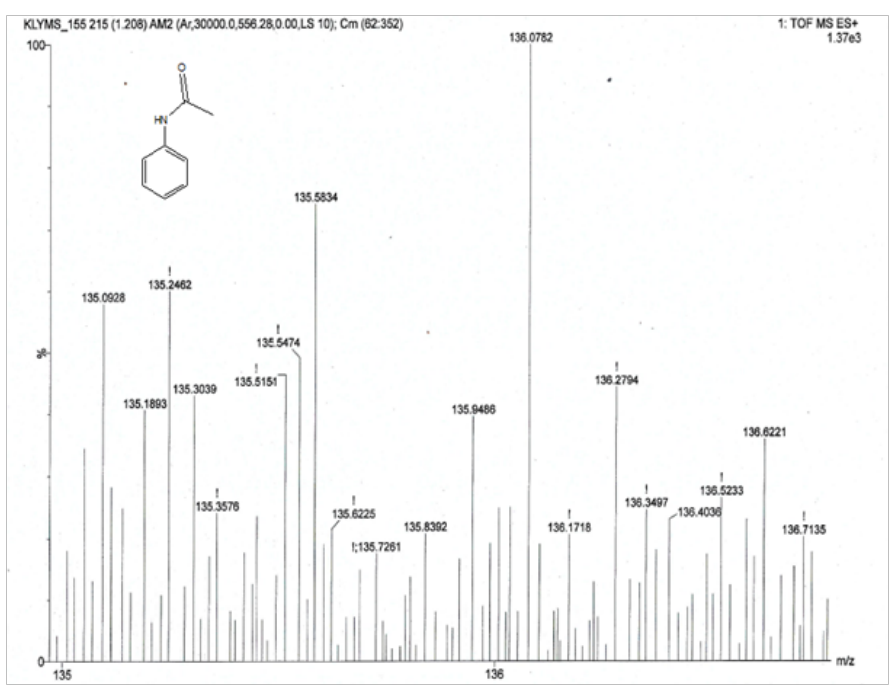

Entry I (Table 2) HRMS m/z calculated for $[M+H]+=\mid 36.0762$, observed $[\mathrm{M}+\mathrm{H}]+=\mid 36.0782$.

With optimized reaction conditions now in hand, the N-acylation of various substituted anilines with acetic acid and phenyl acetic acid was explored and the results are presented in Table 2. It may be observed that the Ag-GO nanocomposite catalysed N-acylation reaction of various substituted anilines with acetic acid afforded good to excellent yields.

Table 2 Acylation of amines with acetic acid over Ag-GO nanocatalyst ${ }^{\mathrm{a}}$<smiles>C=CCCCCOCCOCCNc1ccccc1</smiles>

Table Continued<smiles>CCOc1ccccc1NC(=O)c1ccccc1N(C)c1ccccc1[N+](=O)[O-]</smiles>

8<smiles>Nc1ccccc1I</smiles><smiles>Nc1ccccc1I</smiles>

75

83

I I<smiles>Cc1ccc(N)c(C)c1</smiles><smiles>CC(=O)Nc1ccc(C)cc1C</smiles><smiles>O=C(Cc1ccccc1)Nc1ccccc1</smiles><smiles>COc1ccc(CC(=O)Nc2ccccc2)cc1</smiles><smiles>O=C(Cc1ccc([N+](=O)[O-])cc1)Nc1ccccc1</smiles>

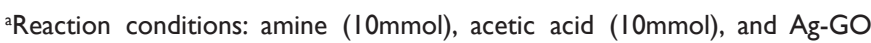
$(25 \mathrm{mg})$, temperature $\left(90^{\circ} \mathrm{C}\right)$, time $4 \mathrm{~h}$. 
The electron withdrawing and donating groups had significant effect on the reaction. While donating groups on aniline led to higher yields, electron withdrawing groups reduced the yield (Table 2, entries $1-4,9)$. The nitro group in para and ortho positions of aniline are expected to cause steric hindrance and nucleophilicity respectively, and thus the related products were obtained in low yields (Table 2, entries 6, 7 and 12). Hence 2-iodo aniline gives higher yield vis-a-vis ortho-and para-nitro aniline (Table 2, entries 6, 7 and 8). Similarly, amines react with phenylacetic acid under same reaction condition to give relatively low yield of product (Table 2 , entries 10-11, 12).

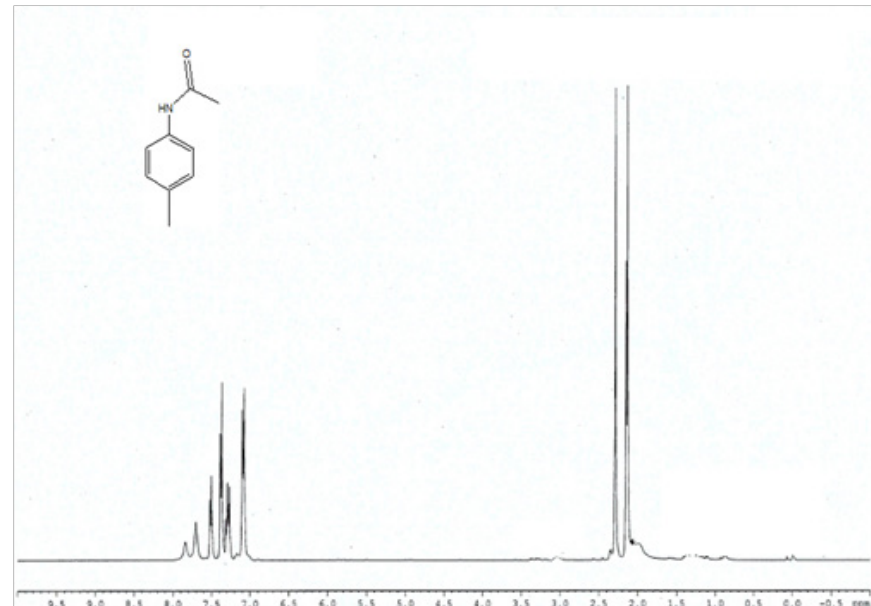

Entry 2 (Table 2) 'H NMR (400MHz; $\left.\mathrm{CDCl}_{3}\right)$; 7.07-7.8 (m, 4H, Ar) 7.I I (t, IH) I.98-2.2 (s, 3H, $\left.\mathrm{CH}_{3}\right), 2.3-2.4\left(\mathrm{~s}, 3 \mathrm{H}, \mathrm{CH}_{3}\right)$,

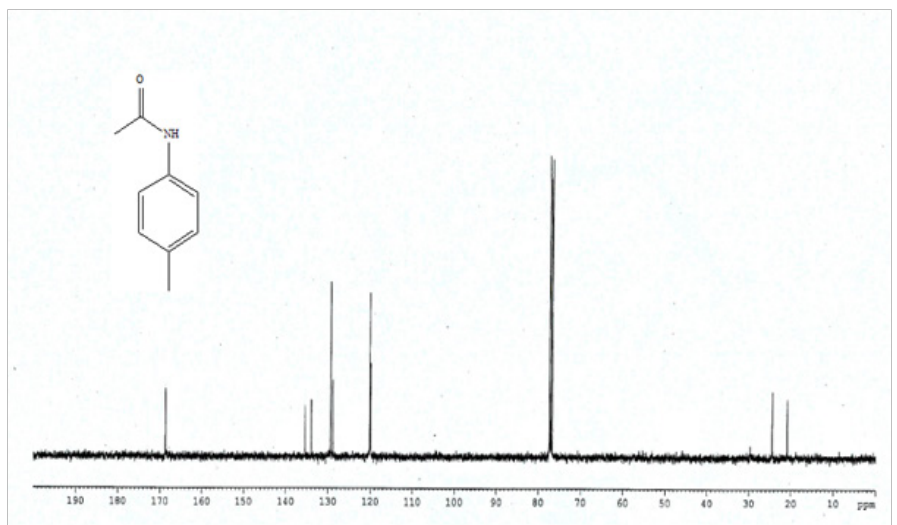

Entry 2 (Table 2) ${ }^{13} \mathrm{C}$ NMR $\left(100 \mathrm{MHz} \mathrm{CDCl}_{3}\right) \delta$ 169.6, 137.8, I35.9, 129.9, | $21.6,21.4,24.4$

Leaching of Ag from the nanocomposite was tested by AAS. After 5 cycles, the amount of Ag in the nanocomposite was found to be $3.89 \%(\mathrm{w} / \mathrm{w})$. Thus, there is negligible leaching of silver from the nanocomposite during catalysis. It is to be noted that the reaction was carried out under ambient conditions, and no extra precautions were taken to preserve or maintain the quality of the catalyst.

Acylation of different substituted amines with acetic acid using several heterogeneous catalysts has been compared in Table 3 below. The table provides a comparison of the results obtained in the present work with those reported in the literature for the same reaction system. ${ }^{41-44}$ From Table 3, it is seen that the Ag-GO nanocomposite catalyst used in this work gave higher yields compared to most of previous reported catalytic systems, and is comparable to the best system reported. ${ }^{40-43}$

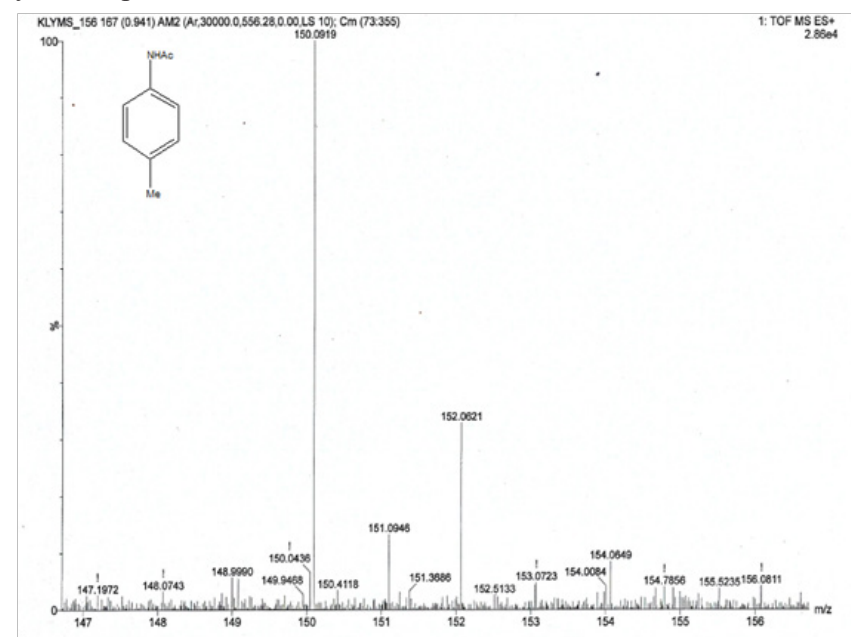

Entry 2 (Table 2) HRMS m/z calculated for $[\mathrm{M}+\mathrm{H}]+=\mid 49.08$ observed $[\mathrm{M}+\mathrm{H}]+=\mid 50.0919$.

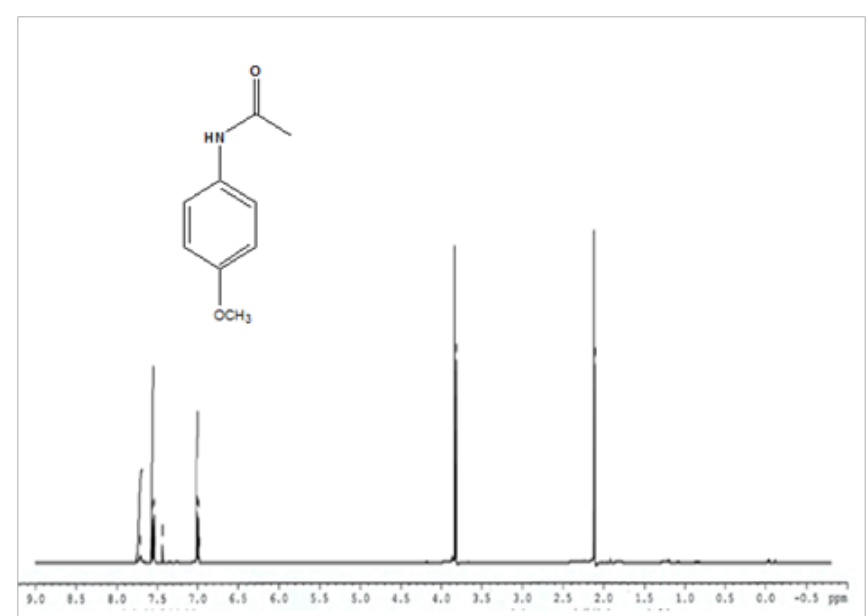

Entry 3 (Table 2) ${ }^{1} \mathrm{H}$ NMR (400MHz; $\mathrm{CDCl}_{3}$ ); 7.1-7.4 (m, 4H, Ar) 1.98-2.2 (s, $\left.3 \mathrm{H}, \mathrm{CH}_{3}\right), 3.3-3.6\left(\mathrm{~s}, 3 \mathrm{H}, \mathrm{CH}_{3}\right)$

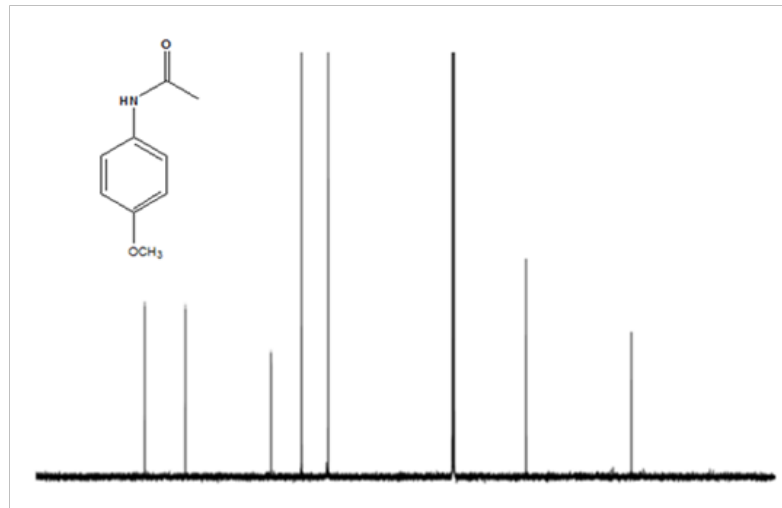

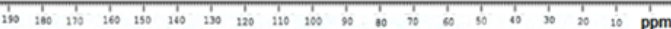

Entry 3 (Table 2) ${ }^{13} \mathrm{C}$ NMR (100MHz; $\left.\mathrm{CDCl}_{3}\right): 168.9,158.9,130.8,122.6$, $114.5,55.8,24.2$; 


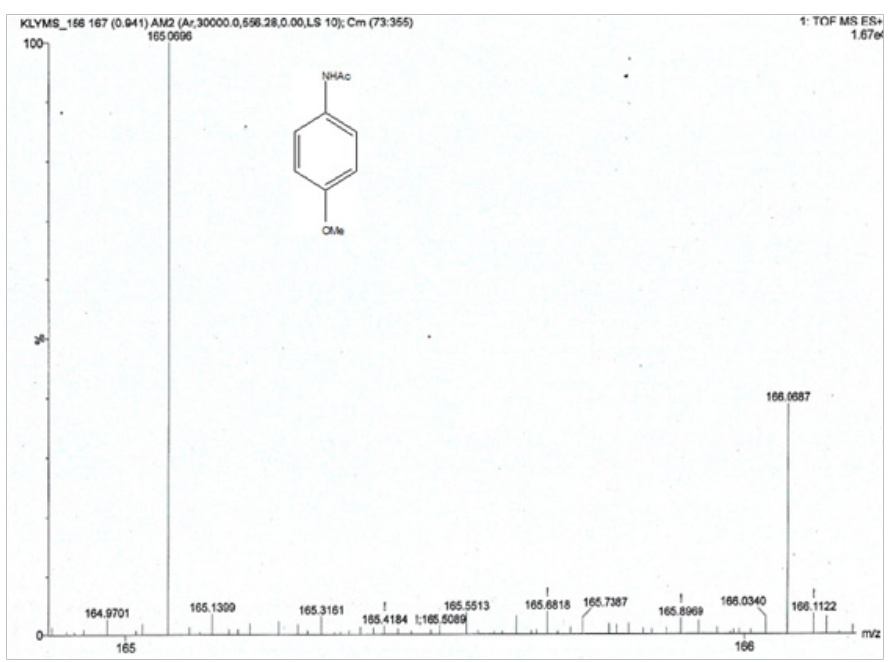

Entry 3 (Table 2) HRMS m/z calculated for $[\mathrm{M}+\mathrm{H}]+=165.08$ observed $[\mathrm{M}+\mathrm{H}]+=165.0696$.

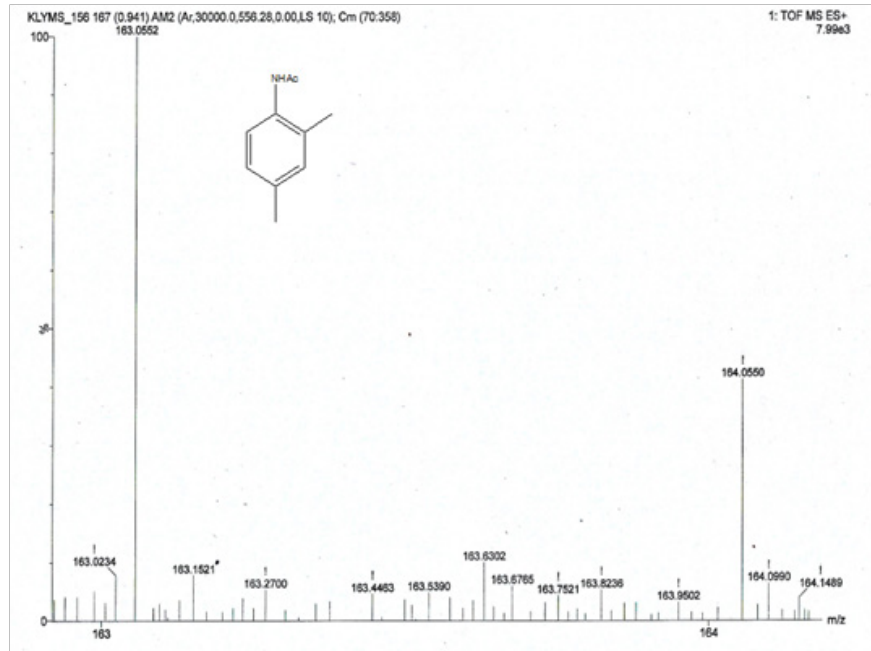

Entry 9 (Table 2) HRMS $\mathrm{m} / \mathrm{z}$ calculated for $[\mathrm{M}+\mathrm{H}]+=163.10$ observed $[\mathrm{M}+\mathrm{H}]+=\mid 63.0552$.

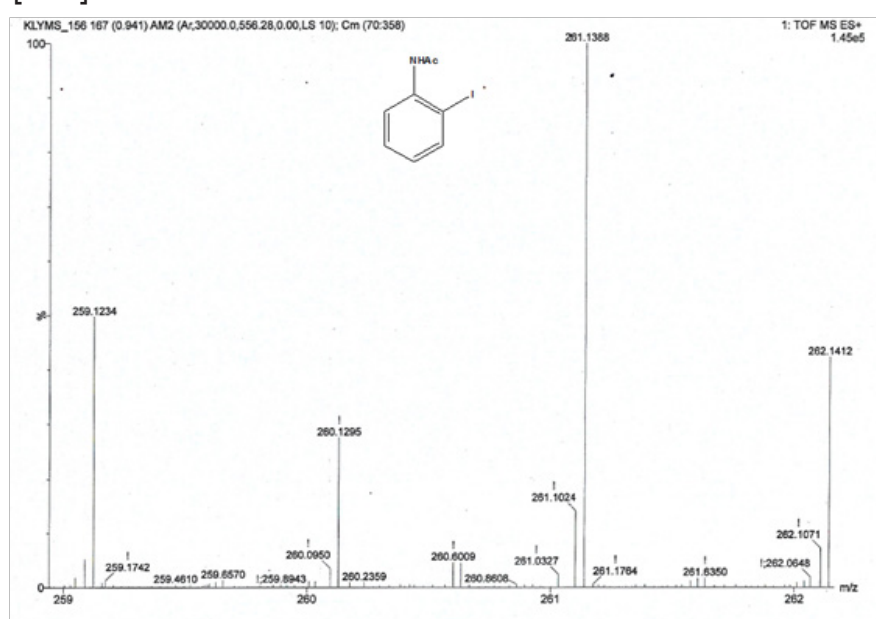

Entry 8 (Table 2) HRMS m/z calculated for $[\mathrm{M}+\mathrm{H}]+=261.97$ observed $[\mathrm{M}+\mathrm{H}]+=261.138$

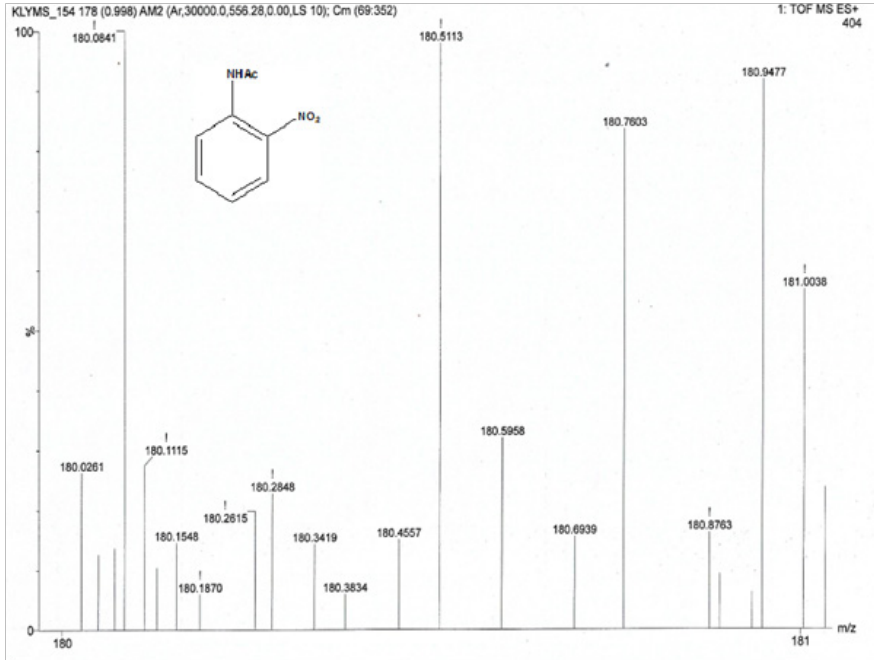

Entry 6 (Table 2) HRMS m/z calculated for $[\mathrm{M}+\mathrm{H}]+=\mid 80.07$ observed $[\mathrm{M}+\mathrm{H}]+=\mid 80.947$

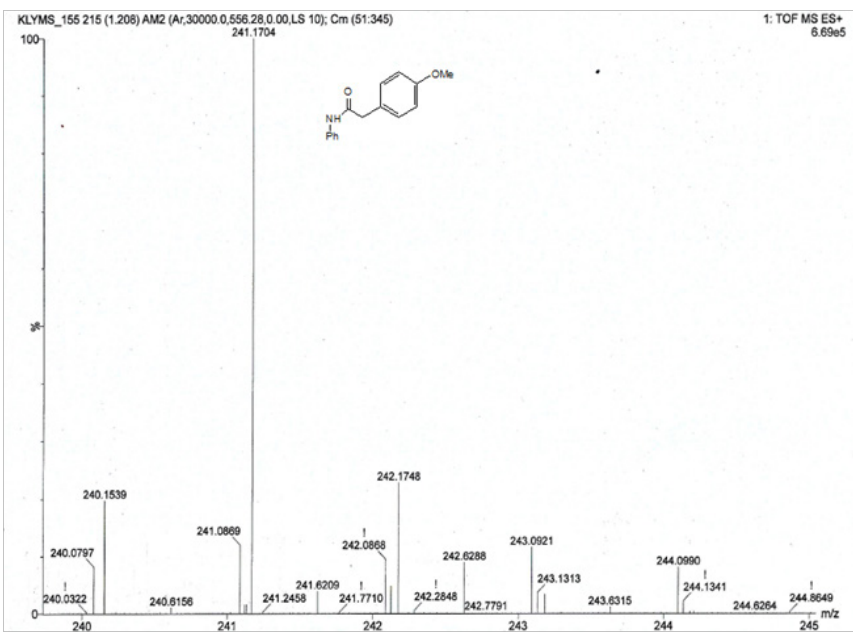

Entry II (Table 2) HRMS m/z calculated for $[\mathrm{M}+\mathrm{H}]+=241.272$ observed $[\mathrm{M}+\mathrm{H}]+=241.170$

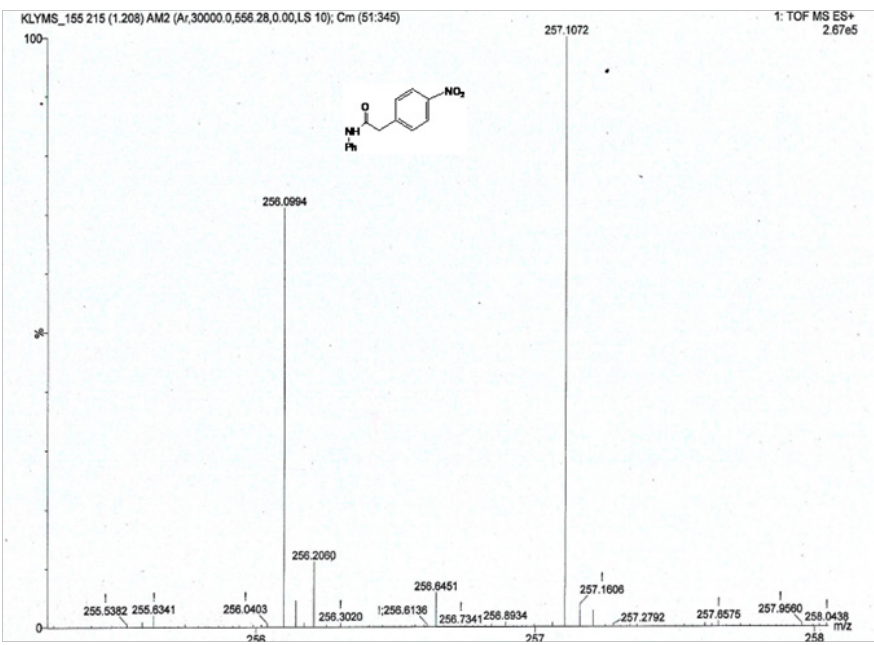

Entry 12 (Table 2) HRMS m/z calculated for $[\mathrm{M}+\mathrm{H}]+=257.172$ observed $[\mathrm{M}+\mathrm{H}]+=257.107$ 


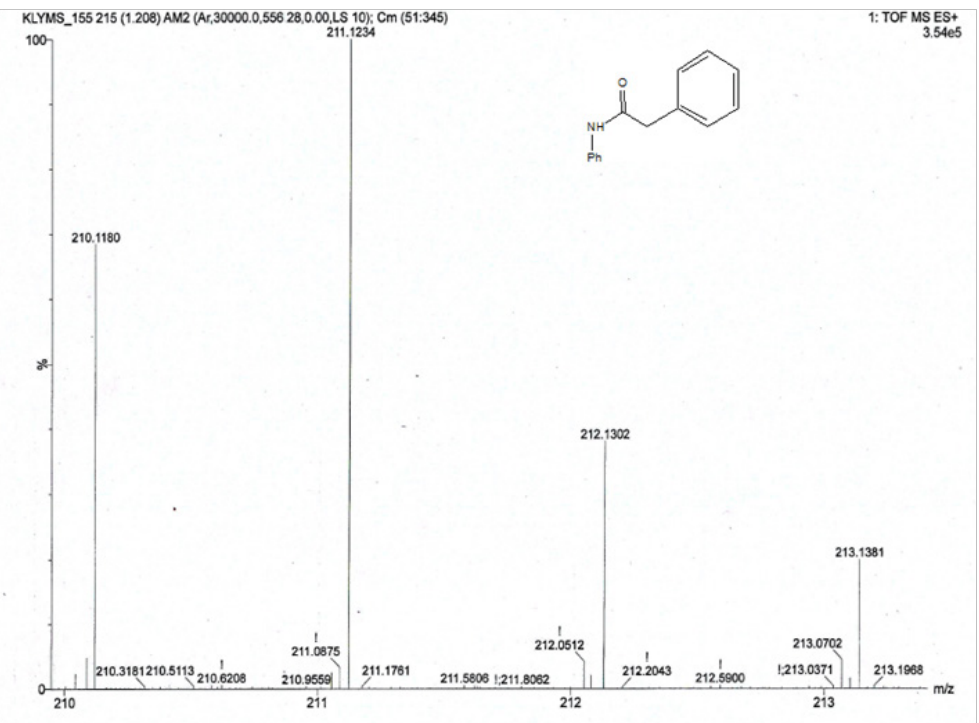

Entry 10 (Table 2) HRMS m/z calculated for $[\mathrm{M}+\mathrm{H}]+=21 \mathrm{I} .132$ observed $[\mathrm{M}+\mathrm{H}]+=21 \mathrm{I} .123$

Table 3 Comparison of catalytic activity of the Ag-GO nanocomposite catalyst in acylation of aniline with previous other reported systems

\begin{tabular}{|c|c|c|c|c|}
\hline $\begin{array}{l}\text { S. } \\
\text { no. }\end{array}$ & Catalyst & Acylation of aniline (reaction conditions) & $\begin{array}{l}\text { Yield } \\
(\%)\end{array}$ & Reference \\
\hline I & $\begin{array}{l}\text { poly }(\mathrm{N}- \\
\text { vinylimidazole })\end{array}$ & Aniline (Immol), $\mathrm{Ac}_{2} \mathrm{O}$ (I mmol), catalyst (20mg), RT & 90 & Zhu et al. ${ }^{40}$ \\
\hline 2 & $\mathrm{Gd}(\mathrm{OTf}) 3$ & Ac2O (27.5mmol), solvent ([bmim][BF4]), catalyst ( $0.2 \mathrm{~mol} \%), \mathrm{RT}$ & 96 & Khaligh et al. ${ }^{41}$ \\
\hline 3 & Zeolite $\mathrm{H} \beta$ & $\begin{array}{l}\text { Aniline }(2 \mathrm{mmol}) \text {, acetic acid }(2 \mathrm{mmol}) \text {, catalyst }(200 \mathrm{mg}) \text {, temperature } \\
\left(117^{\circ} \mathrm{C}\right) \text {, under microwave irradiation }\end{array}$ & 74 & Alleti et al..$^{42}$ \\
\hline 4 & mPANI/Ag & $\begin{array}{l}\text { Aniline }(10 \mathrm{mmol}) \text {, acetic acid }(10 \mathrm{mmol}) \text {, catalyst }(25 \mathrm{mg}) \text {, temperature } \\
\left(140^{\circ} \mathrm{C}\right)\end{array}$ & 98 & Krishna et al. ${ }^{43}$ \\
\hline 5 & $\begin{array}{l}\text { Silver-graphene } \\
\text { oxide(Ag-GO) } \\
\text { nanocomposite }\end{array}$ & $\begin{array}{l}\text { Aniline }(0.9 \mathrm{~mL}, 10 \mathrm{mmol}) \text {, acetic acid }(0.6 \mathrm{~mL}, 10 \mathrm{mmol}) \text {, catalyst }(25 \mathrm{mg}) \text {, } \\
\text { temperature }\left(90^{\circ} \mathrm{C}\right)\end{array}$ & 97 & Present study \\
\hline
\end{tabular}

\section{Recyclability of Ag-GO nanocatalyst}

In case of heterogeneous catalyst, it is crucial to test its recoverability and reusability. The reusability of Ag-GO nanocomposite was checked in $\mathrm{N}$-acylation reaction of aniline with acetic acid. After completion of each run, the reaction medium was filtered, the filtrate was collected and the resulting residue was washed with water several times followed by ethanol. The residue was then dried in air and used in the next run. Very little loss of activity was observed after five consecutive cycles (Figure 11). Thus the catalyst can be efficiently reused for at least five cycles without any significant loss in activity. The possible mechanism of acylation reaction amine with acetic acid in the presence of $\mathrm{Ag}-\mathrm{GO}$ nanocomposite catalyst under solvent free condition is shown in Figure 12. It is assumed that due to bonding of $\mathrm{C}=\mathrm{O}$ with $\mathrm{Ag}-\mathrm{GO}$ nanocomposite, the carbon atom becomes more prone to electrophilic attack (by the amine). The amide bond is stabilized by dehydration.

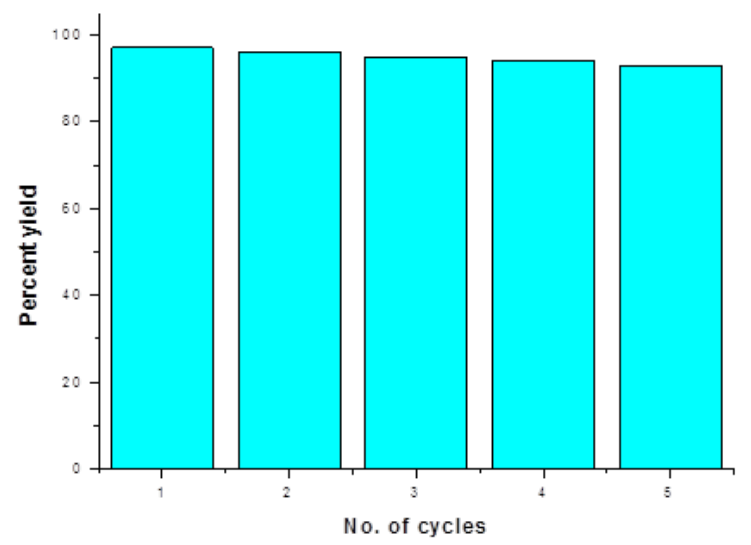

Figure I I Recycling activity of the Ag-GO catalyst. 


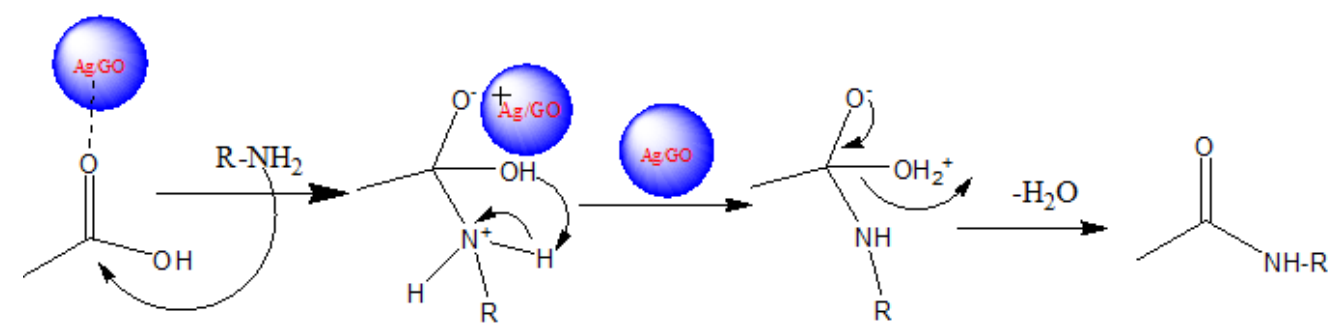

\begin{abstract}
Electrophilicity of carbonyl carbon of acetic acid incresed in presence of catalyst $(\mathrm{Ag} / \mathrm{GO})$ nanocomposite
\end{abstract}

Figure $\mathbf{I} 2$ possible mechanism of acylation reaction.

\section{Conclusion}

A new graphene oxide based composite with silver nanoparticles has been synthesized. The resulting nanocomposite acts as a heterogeneous catalyst, showing reasonable catalytic activity for the $\mathrm{N}$-acylation reaction of aniline and acetic acid. The catalytic process is green and offers a number of advantages, such as easy work-up and separation of the catalyst from the reaction mixture by filtration, reusability for several times with minimal loss of activity. These key findings make the nanocomposite a desirable heterogeneous catalyst which is recyclable, economical, green and environmentally sustainable.

\section{Funding source}

There was no separate funding for this work

\section{Acknowledgements}

The authors gratefully acknowledge the infrastructural support from DST-FIST and UGC-SAP (DRS II) grants to the Department of Chemistry, University of Kalyani. Infrastructural support from DST-PURSE grant to the Faculty of Science of the university is also acknowledged. PM acknowledges financial support from RGNF from UGC, New Delhi for his Senior Research Fellowship. ANC acknowledges financial support from INSPIRE Fellowship from DST, New Delhi. We thank Dr. A. Singha, Bose Institute, Kolkata, India for help with Raman spectrum.

\section{Conflict of interest}

Author declares that there is no conflict of interest in this work.

\section{References}

1. Burda C, Chen Z, Narayanan R, et al. Chemistry and properties of nanocrystals of different shapes. Chem Rev. 2005;105(4):1025-1102.

2. Laurent S, Forge D, Port M, et al. Magnetic iron oxide nanoparticles: synthesis, stabilization, vectorization, physicochemical characterizations, and biological applications. Chem Rev. 2008;108(6):2064-2110.

3. Chen XT, Yamaguchi A, Namekawa, et al. Functionalization of mesoporous silica membrane with a Schiff base fluorophore for $\mathrm{Cu}(\mathrm{II})$ ion sensing. Anal Chim Acta. 2011;696(1-2):94-100.
4. Polshettiwar V, Baruwati B, Varma RS. Self-assembly of metal oxides into three-dimensional nanostructures: synthesis and application in catalysis. ACS Nano. 2009;3:728-736.

5. Huang J, Yin J, Chai W, C. et al. Multifunctional mesoporous silica supported palladium nanoparticles as efficient and reusable catalyst for water-medium Ullmann reaction. New J Chem. 2012;36(6):1378-1384.

6. Sachtler WMH. Metal clusters in zeolites: an intriguing class of catalysts. Acc Chem Res. 1993;26(7):383-387.

7. Jong KPD, Geus JW. Carbon Nanofibers: Catalytic Synthesis and Applications. Catal Rev Sci Eng. 2000;42(4):481-510.

8. Yao KX, Liu X, Li Z, et al. Preparation of a Ru-nanoparticles/defectivegraphene composite as a highly efficient arene-hydrogenation catalyst. Chem Cat Chem. 2012;4(12):1938-1942.

9. Huang X, Yin Z, Wu S, et al. Graphene-based materials: synthesis, characterization, properties, and applications. Small. 2011;7(14):18761902.

10. Kamat PV. Graphene-Based Nanoarchitectures. Anchoring Semiconductor and Metal Nanoparticles on a Two-Dimensional Carbon Support. J Phys Chem Lett. 2010;1(2):520-527.

11. Chen L, Yang K, Liu H, et al. Carbon. 2008;46:213-218.

12. Guo S, Wen D, Zhai Y, et al. Platinum Nanoparticle Ensemble-onGraphene Hybrid Nanosheet: One-Pot, Rapid Synthesis, and Used as New Electrode Material for Electrochemical Sensing. ACS Nano. 2010;4(7):3959-3968.

13. Hong W, Bai H, Xu Y, et al. Preparation of Gold Nanoparticle/Graphene Composites with Controlled Weight Contents and Their Application in Biosensors. J Phys Chem C. 2010;114(4):1822-1826.

14. Chen X, Wu G, Chen J, et al. Synthesis of "clean" and well-dispersive Pd nanoparticles with excellent electrocatalytic property on graphene oxide. J Am Chem Soc. 2011;133:3693-3695.

15. Sawangphruk M, Suksomboon M, Kongsupornsak K, et al. J Mater Chem A. 2013;229:460-468.

16. Jasuja K, Linn J, Melton S, et al. Microwave-Reduced Uncapped Metal Nanoparticles on Graphene: Tuning Catalytic, Electrical, and Raman Properties. J Phys Chem Lett. 2010;1(12):1853-1860.

17. Scheuermann GM, Rumi L, Steurer P, et al. Palladium nanoparticles on graphite oxide and its functionalized graphene derivatives as highly active catalysts for the Suzuki-Miyaura coupling reaction. J Am Chem 
Soc. 2009; 131(23):8262-8270.

18. Moussa S, Siamaki AR, Gupton MS, et al. Pd-Partially Reduced Graphene Oxide Catalysts (Pd/PRGO): Laser Synthesis of $\mathrm{Pd}$ Nanoparticles Supported on PRGO Nanosheets for Carbon-Carbon Cross Coupling Reactions. ACS Catal. 2012;2(1):145-154.

19. Li Q, Guo B, Yu J, et al. Highly Efficient Visible-Light-Driven Photocatalytic Hydrogen Production of CdS-Cluster-Decorated Graphene Nanosheets. J Am Chem Soc. 2011;133(128):10878-10884.

20. Song B, Lai MO, Liu Z, et al. Graphene-based surface modification on layered Li-rich cathode for high-performance Li-ion batteries. J Mater Chem A. 2013;1(34):9954-9965.

21. Villaverde G, Corma A, Iglesias M, et al. Heterogenized Gold Complexes: Recoverable Catalysts for Multicomponent Reactions of Aldehydes, Terminal Alkynes, and Amines. ACS Catal. 2012;2(3):399-406.

22. Choudhury A, Polyaniline/silver nanocomposites: Dielectric properties and ethanol vapour sensitivity. Sensors and Actuators B: Chemical. 2009;138:318-325.

23. Salam N, Sinha A, Roy AS, et al. Synthesis of silver-graphene nanocomposite and its catalytic application for the one-pot threecomponent coupling reaction and one-pot synthesis of 1,4-disubstituted 1,2,3-triazoles in water. RSC Adv. 2014;4:10001-10012.

24. Jia H, Hou W, Wei L, et al. The structures and antibacterial properties of nano-SiO, supported silver/zinc-silver materials. Dent Mater. 2008;24(2):244-249.

25. Hsu SH, Tseng HJ, Lin YC. The biocompatibility and antibacterial properties of waterborne polyurethane-silver nanocomposites. Biomaterials. 2010;31(26):6796-6808.

26. $\mathrm{Xu}$ P, Jeon $\mathrm{SH}$, Chen HT, et al. Facile Synthesis and Electrical Properties of Silver Wires through Chemical Reduction by Polyaniline. J Phys Chem C. 2010;114(50):22147-22154.

27. Salam N, Banerjee B, Singha Roy A, et al. Silver nanoparticles embedded over mesoporous organic polymer as highly efficient and reusable nanocatalyst for the reduction of nitroarenes and aerobic oxidative esterification of alcohols. Appl Catal A: Gen. 2014;477:184-194.

28. Krutyakov YA, Kudrinsky AA, Yu A, et al. Synthesis of highly stable silver colloids stabilized with water soluble sulfonated polyaniline. Appl Surf Sci. 2010;256(23):7037-7042.

29. Larock RC. Comprehensive Organic Transformations. $2^{\text {nd }}$ ed. New York VCH Publishers; 1989.

30. Greene TW, Wuts PGM. Protective Groups in Organic synthesis, $3^{\text {rd }}$ ed. New York: John Wiley \& Sons; 1999.
31. Carey JS, Laffan D, Thomson C, et al. Analysis of the reactions used for the preparation of drug candidate molecules. Org Biomol Chem. 2006;4(12):2337-2347

32. Cope AC, Herrich EC. Organic Synthesis Collective. New York:Wiley;1963.

33. Breton GW, Kurtz MJ, Kurtz SL. Acetylation of unsymmetrical diols in the presence of $\mathrm{Al}_{2} \mathrm{O}_{3}$. Tetrahedron Lett. 1997;38(22):3825-3828.

34. Hagiwara H, Morohashi K, Suzuki T, et al. Synth Commun. 1998;28:2001-2006.

35. Chandra KL, Saravan P, Singh RK, et al. Lewis acid catalyzed acylation reactions: scope and limitations. Tetrahedron. 2002;58:1369-1374.

36. Das R, Chakraborty D. Silver Triflate Catalyzed Acetylation of Alcohols, Thiols, Phenols, and Amines Rima Das, Debashis Chakraborty*. Synthesis. 2011;10:1621-1625.

37. Pansare SV, Malusare MG, Rai AN. Magnesium Bromide Catalysed Acylation of Alcohols. Synth Commun. 2000;30(14):2587-2592.

38. Baltork IM, Aliyan H, Khosropour AR. Bismuth(III) salts as convenient and efficient catalysts for the selective acetylation and benzoylation of alcohols and phenols. Tetrahedron. 2001;57(27):5851-5854.

39. Chook SW, Chia $\mathrm{CH}$, Zakaria S, et al. Antibacterial performance of Ag nanoparticles and $\mathrm{AgGO}$ nanocomposites prepared via rapid microwaveassisted synthesis method. Nanoscale Res Lett. 2012;7:541-548.

40. Zhu C, Guo S, Fang Y, et al. Reducing sugar: new functional molecules for the green synthesis of graphene nanosheets. ACS Nano. 2010;4(4):2429-2437.

41. Khaligh NG. $\operatorname{Poly}(N$-vinylimidazole) as an efficient catalyst for acetylation of alcohols, phenols, thiols and amines under solvent-free conditions. RSC Adv. 2013;3(1):99-110.

42. Alleti R, Oh WS, Perambuduru M, et al. Gadolinium triflate immobilized in imidazolium based ionic liquids: a recyclable catalyst and green solvent for acetylation of alcohols and amines. Green Chem. 2005;7:203-206.

43. Krishna Mohan KVV, Narender N, Kulkarni SJ. Zeolite catalyzed acylation of alcohols and amines with acetic acid under microwave irradiation. Green Chem. 2006;8:368-372.

44. Mandi U, Singha Roy A, Banerjee B, et al. A novel silver nanoparticle embedded mesoporous polyaniline (mPANI/Ag) nanocomposite as a recyclable catalyst in the acylation of amines and alcohols under solvent free conditions. RSC Adv. 2014;4(80):42670-42681. 